\title{
Theism and Dialetheism
}

\author{
A. J. COTNOIR
}

\begin{abstract}
The divine attributes of omniscience and omnipotence have faced objections to their very consistency. Such objections rely on reasoning parallel to the semantic paradoxes such as the Liar or the set-theoretic paradoxes like Russell's paradox. With the advent of paraconsistent logics, dialetheism — the view that some contradictions are true — became a major player in the search for a solution to such paradoxes. This paper explores whether dialetheism, armed with the tools of paraconsistent logics, has the resources to respond to the objections levelled against the divine attributes.
\end{abstract}

Traditional monotheists usually agree: God is essentially omnipotent and omniscient. ${ }^{1}$ Yet many of the logical objections to monotheism concern these divine attributes. The objections purport to show that, on pain of inconsistency, there is no God in the traditional theist's sense.

Some philosophers, notably Descartes [I2], Frankfurt [I3], and Conee [Io], have defended theism by accepting some forms of inconsistency. They endorse the claim that God is able to know true contradictions or is able to bring about inconsistent states of affairs. Unfortunately, the view has never been worked out in any logical detail. In the last half-century, the development of paraconsistent logics has given philosophers ways to reason about inconsistent theories. Dialetheism, the view that some contradictions can be true, has recently been defended as a way to handle all the semantic and set-theoretic paradoxes. But the paradoxes of omnipotence and omniscience are parallel to the semantic and set-theoretic paradoxes. So dialetheism and paraconsistent logic should prove helpful in developing an inconsistent theory of classical monotheism.

\footnotetext{
${ }^{0}$ This is a preprint of an article whose final and definitive form will be published in the Australasian Journal of Philosophy available online at: http://www.tandf.co.uk/journals/.

${ }^{1}$ See [34] for medieval Islamic, Jewish, and Christian perspectives.
} 
The purpose of this article is largely exploratory: I examine how dialetheic theories might respond to the paradoxes of the divine attributes, making full use of paraconsistent logic. I argue that if we grant the theist all the resources of dialetheism and paraconsistency the paradoxes are not logically problematic. The formal implementation of these logics, however, lead to some additional consequences which theists may find troubling. The dialetheic theist can accept that God is omnipotent and omniscient, but only at the cost of also accepting that God is also not omnipotent and not omniscient; omniscience and omnipotence are inconsistent properties. I also discuss whether the view is committed to the more troubling claim that God both does and does not exist. I motivate and develop a number of ways dialetheic theists might attempt to avoid these consequences by limiting the spread of inconsistency. Finally, I close by considering whether any specific form of dialetheism is better-motivated within some theological traditions.

\section{Preliminaries}

\section{I.I Motivations}

Ompotence and omniscience appear to implicitly quantify over absolutely everything. When we assert God's omnipotence, we typically claim that there is nothing, no event or state of affairs, that God cannot bring about. Similarly, when we assert God's omniscience we typically claim that there is nothing, no true proposition, that God does not or cannot know. But the paradoxes of omnipotence and omniscience purport to show that an absolutely unrestricted reading of these claims leads directly to contradiction. The standard reply to these paradoxes is to claim that the paradoxical events or propositions — by virtue of being contradictory — are impossible, and hence not a member of the domain of quantification. But in some cases the events or propositions in question are not obviously logically impossible simpliciter, but merely incompatible with the existence of an omniscient or omnipotent being. There is a prima facie worry that the standard reply attempts to explain away counterexamples by restricting the domain of quantification. These issues are dialectically delicate, but one thing is for certain: much ink has been devoted to 
defending consistent solutions to the omni-paradoxes. Almost none has been devoted to a dialetheist solution to the logical problems for theism, despite the fact that it is a strong contender in directly parallel debates in philosophical logic.

Theists have theological reasons for taking the dialetheic view seriously, too, by virtue of their commitment to God's aseity. God has ontologically priority over everything else; chains of ontological dependence must always 'ground out' in God. Descartes tied ontological priority to omnipotence:

The mathematical truths which you call eternal have been laid down by God and depend upon him entirely no less than the rest of his creatures. Indeed to say that theses truths are independent of God is to talk of him as if he were Jupiter or Saturn and to subject him to the Styx and the Fates. Please do not hesitate to assert and proclaim everywhere that it is God who has laid down these laws in nature just as a king lays down laws in his kingdom. [...]

It will be said that if God has established these truths he could change them as a king changes his laws. To this the answer is: Yes he can, if his will can change. [...] In general we can assert that God can do everything that is within our grasp but not that he cannot do what is beyond our grasp. It would be rash to think that our imagination reaches as far as his power. ('To Mersenne', [ I 2, p. 23])

More specifically, regarding contradictions he writes:

I turn to the difficulty of conceiving how God would have been acting freely and indifferently if he had made it false that the three angles of a triangle should equal two right angles, or generally that contradictories could not be true together. It is easy to dispel this difficulty by considering that the power of God cannot have any limits [...] God cannot have been determined to make it true that contradictories cannot be true together, and therefore that he could have done the opposite. ('To Mesland', [I 2, p. 235] 
If God is prior to logical principles, or that God 'cannot have been determined' to act consistently by the law of non-contradiction, then there is motivation for a dialetheic approach.

A brief aside: there may be good reason to drive a wedge between 'God can do $x$ ' and 'it's logically possible that God does $x^{\prime}$. A statement of the former need not commit one to the latter if there is some broader notion of possibility than logical possibility in play. So, one might think that contradictions are logically impossible, and yet, theologically possible. Indeed, Conee [ı ] seems to come close to this sort of view. Such a view would appear to require a background paraconsistent logic, as we would need to have models with inconsistent worlds or states of affairs. It may be tempting to think that this view might be non-dialetheic, however, as we will see below, contradictions have a tendency to 'spread' from impossible worlds to possible ones, and from possible worlds to the actual world. In what follows, then, I will make a simplifying assumption and identify logical possibility with theological possibility, assuming the statement 'God can do $x$ ' is equivalent to 'it's logically possible that God does $x^{\prime} .^{2}$

\section{I.2 Dialetheism and Paraconsistent Logic}

Dialetheism is the view that contradictions - sentences of the form $A \wedge \neg A-$ can be true. Following Restall [33], we distinguish two kinds of dialetheism: full-strength dialetheism is the view that there (actually) are true contradictions, and light dialetheism is the view that it is possible for contradictions to be true, but there aren't any (actually).

In classical logic, the following rule of inference is valid.

$$
A \wedge \neg A \vDash B
$$

This inference is called ex contradictione sequitur quodlibet (ECQ); it claims that any sentence $B$ follows from a contradiction. A dialetheist must reject ECQ on pain of a commitment to

\footnotetext{
${ }^{2}$ That is not to say that there isn't interesting work to be done in this area, but I will not attempt to do it here. I hope to address some of these questions in future work.
} 
trivialism i.e. a commitment to the truth of every sentence. Logics for which ECQ fails are called paraconsistent logics; they allow for consideration of contradictory but non-trivial theories. It will be useful, then, to consider what consequences are in the offing for dialetheic theism by appealing to a paraconsistent logic.

The basic paraconsistent logic most useful for our purposes is Priest's [25] quantified Logic of Paradox, or $L P$, extended to include modal operators. Of all the paraconsistent logics, the semantics for $L P$ are the simplest, and a minimal revision to classical logic - indeed, it has classical logic as a proper extension. Notably, all the classical logical truths are logical truths of $L P$.

The syntax of $L P$ is usual; we also include the symbols for alethic modality: $\square$ and $\diamond . L P$ is a three-valued logic. In classical logic, the set of values $V=\{1,0\}$ has 1 as the only designated value. In $L P, V=\left\{1, \frac{1}{2}, 0\right\}$ and is ordered thus: $1>\frac{1}{2}>0$. One can think of the value $\frac{1}{2}$ as 'both true and false'. Importantly, in $L P$ both 1 and $\frac{1}{2}$ are designated values.

The models of $L P$ are structures: $\langle W, D, \nu\rangle$. Here $W$ is a non-empty set of 'worlds' ${ }^{3} D$ is our non-empty domain of objects. Here, $\nu$ is an interpretation function that satisfies (a)-(l) below. ${ }^{4}$

a. For every name $c, \nu(c) \in D .^{5}$

b. For every $n$-ary predicate $P$ and $w \in W, \nu_{w}^{+}(P) \subseteq D^{n}$ and $\nu_{w}^{-}(P) \subseteq D^{n}$ and $\nu_{w}^{+}(P) \cup \nu_{w}^{-}(P)=$ $D^{n}{ }^{6}$

c. For every $n$-ary predicate $P$ and terms $a_{1}, \ldots, a_{n}, \nu_{w}\left(P\left(a_{1}, \ldots, a_{n}\right)\right)=1$ iff $\left\langle\nu\left(a_{1}\right), \ldots, \nu\left(a_{n}\right)\right\rangle \in$

\footnotetext{
${ }^{3}$ Standard frames for normal modal logics have an accessibility relation on worlds $R \subseteq W \times W$. For modal operators I am presupposing 'universal access' and so drop $R$ for simplicity.

${ }^{4}$ The approach here is a combination of the many-valued first-order logics given in Priest [28, ch. 2I] and the modal semantics given in Priest [29, p. I93].

${ }^{5}$ Let us stipulate, for simplicity, that every object in the domain has a name. We have taken a fixed-domain approach to the semantics, so that all of our names are rigid; for any $w$ and $w^{\prime}$ in $W, \nu_{w}(c)=\nu_{w^{\prime}}(c)$.

${ }^{6} D^{n}$ is the $n$th Cartesian product of the domain, so $D \times D \times \ldots \times D n$-many times. Thus, $\nu$ gives the extensions and anti-extensions of our predicates. The extension, + , is the set of objects in the domain of which the predicate is true. The anti-extension, - , is the set of objects in the domain of which the predicate is false. The extensions and anti-extensions are relative to a world; that is, $\nu_{w}(P)$ need not be the same as $\nu_{w^{\prime}}(P)$. Like classical logic, the union of $\nu_{w}^{+}(P)$ with $\nu_{w}^{-}(P)$ is the entirety of the domain, thus we have no truth-value 'gaps'. This latter assumption is not required, and may even be disadvantageous. See Beall and Cotnoir [6].
} 
$\nu_{w}^{+}(P)$ and $\left\langle\nu\left(a_{1}\right), \ldots, \nu\left(a_{n}\right)\right\rangle \notin \nu_{w}^{-}(P)$

d. $\nu_{w}\left(P\left(a_{1}, \ldots, a_{n}\right)\right)=\frac{1}{2}$ iff $\left\langle\nu\left(a_{1}\right), \ldots, \nu\left(a_{n}\right)\right\rangle \in \nu_{w}^{+}(P)$ and $\left\langle\nu\left(a_{1}\right), \ldots, \nu\left(a_{n}\right)\right\rangle \in \nu_{w}^{-}(P)^{7}$

e. $\nu_{w}\left(P\left(a_{1}, \ldots, a_{n}\right)\right)=0$ iff $\left\langle\nu\left(a_{1}\right), \ldots, \nu\left(a_{n}\right)\right\rangle \notin \nu_{w}^{+}(P)$ and $\left\langle\nu\left(a_{1}\right), \ldots, \nu\left(a_{n}\right)\right\rangle \in \nu_{w}^{-}(P)$

f. For every variable $v$ and formula $A$ with only $v$ free, $\nu_{w}(\forall v A)=\min \left\{\nu_{w}\left(A_{v}(c)\right)\right.$ : for all names $c\}^{8}$

g. $\nu_{w}(\exists v A)=\max \left\{\nu_{w}\left(A_{v}(c)\right)\right.$ : for all names $\left.c\right\}$

h. For all sentences $A$ and $B, \nu_{w}(A \wedge B)=\min \left\{\nu_{w}(A), \nu_{w}(B)\right\}$

i. $\nu_{w}(A \vee B)=\max \left\{\nu_{w}(A), \nu_{w}(B)\right\}$

j. For every sentence $A, \nu_{w}(\neg A)=1-\nu_{w}(A)$

k. $\nu_{w}(\square A)=\min \left\{\nu_{w^{\prime}}(A)\right.$ : for all $\left.w^{\prime}\right\}$

1. $\nu_{w}(\diamond A)=\max \left\{\nu_{w^{\prime}}(A)\right.$ : for all $\left.w^{\prime}\right\}$

Let $\supset$ and $\equiv$ be defined as $\neg A \vee B$ and $(\neg A \vee B) \wedge(\neg B \vee A)$ respectively. A sentence is satisfied (in-a-model, at-a-world) iff the value of that sentence (in-the-model, at-that-world) is designated. An argument from a set of premises $X$ to a conclusion $A$ is valid $(X \vDash A)$ iff every model which satisfies $X$ at some world, satisfies $A$ at that world.

I note two useful facts. As in classical normal modal logics, the modal operators are interdefinable:

(2) $\neg \diamond \neg A \vDash_{L P} \square A$

${ }^{7}$ Here we allow for the possibility that $\nu_{w}^{+}(P)$ and $\nu_{w}^{-}(P) \neq \varnothing$ have a non-empty intersection, resulting in truth-value 'gluts'.

${ }^{8} A_{v}(c)$ abbreviates the result of substituting some name $c$ for all free occurrences of $v$ in $A$. This takes the place of variable assignments, since we have stipulated that all objects in the domain have a name. These semantics for quantifiers in many-valued logic are fairly typical; see Priest [28]. 
Likewise, as in classical first-order logic, the quantifiers are interdefinable:

$$
\forall v A \vDash_{L P} \neg \exists v \neg A
$$

It is well-known that disjunctive syllogism fails in paraconsistent logics. Since the material conditional, $\supset$, is simply a disguised disjunction, it follows that material modus ponens fails:

$$
A, A \supset B \#_{L P} B
$$

Letting $\nu_{w}(A)=\frac{1}{2}$ and $\nu_{w}(B)=0$ yields a counterexample. There is much debate over which conditional is the 'correct' one for paraconsistent logics. Adding a detachable conditional often brings with it the troublesome issues surrounding Curry's paradox. While the choice of a suitable conditional is largely beside the main point of this paper (most of argued-for results turn on the semantics for the quantifiers or modal operators), some issues arise in $\S_{4}$ which directly relate to this choice. One of the most plausible paraconsistent conditionals is found in the logic $D K Q$ ([27, p. 25 I], [39], [40]). (A brief presentation of DKQ can be found in the Appendix.) The conditional, which we will write ' $\rightarrow$ ', satisfies modus ponens, identity, contraposition, and many other intuitive conditional rules; it does this all while avoiding Curry's paradox and the related logical principles that allow for its derivation. ${ }^{9}$ We can define a $D K Q$ biconditional as follows: $A \leftrightarrow B$ iff $(A \rightarrow B) \wedge(B \rightarrow A)$. For our purposes, we will use $D K Q$ where issues require a detachable conditional. Where they do not, we will simply rely on $L P$ reasoning. Armed with paraconsistent logic in the background, we can now return to our main task: evaluating the omni-paradoxes.

${ }^{9}$ The $D K Q$ conditional does not have a truth table, but is sound with respect to the truth table of the conditional in $R M_{3}$, given below.

\begin{tabular}{c|ccc}
$\rightarrow$ & 1 & $\frac{1}{2}$ & 0 \\
\hline 1 & 1 & 0 & 0 \\
$\frac{1}{2}$ & 1 & $\frac{1}{2}$ & 0 \\
0 & 1 & 1 & 1
\end{tabular}

Since anything invalid by the $R M_{3}$ truth tables is also $D K$ invalid, this can be a useful way of checking for inferences that break down. 


\section{The Paradox of the Stone}

The paradox of the stone begins with a question: can God create a stone too heavy for him to lift? The following argument is meant to show that, whatever the answer, God is not omnipotent. ${ }^{10}$

i. Either God can create a stone which he cannot lift or he cannot.

ii. If God can create a stone which he cannot lift, then God cannot do everything.

iii. If God cannot create a stone which he cannot lift, then God cannot do everything.

iv. Therefore God is not omnipotent.

The argument is meant to undermine an unrestricted notion of omnipotence. Where $B$ is a binary predicate standing for the relation of $x$ bringing about some event $y$ :

$$
x \text { is omnipotent } \leftrightarrow \forall y(\diamond B(x, y))
$$

An omnipotent being is such that for events $y$, it is possible for that being to bring about $y$.

\section{I Consistent Responses}

The standard line of response, originating from Aquinas and defended by contemporary theists, is to deny (iii). The contention is that God need not be required to do the logically impossible in order to be omnipotent. All that is required for omnipotence is the ability to do what is possible to be done.

$$
x \text { is omnipotent } \leftrightarrow \forall y(\diamond \exists z B(z, y) \rightarrow \diamond B(x, y))
$$

Here we require an omnipotent being to be able to bring about any event that is logically possible to bring about.

\footnotetext{
${ }^{10}$ There are many different versions of the paradox, but perhaps the best version is due to Homer Simpson, who asked: "Can Jesus microwave a burrito so hot that he himself cannot eat it?", which as far as melon-scratchers go is a honey doodle [37].
} 
One trouble with this line of response: there is nothing logically impossible about the description ' $x$ is able to make a thing too heavy for $x$ to lift'. ${ }^{11}$ It is perfectly consistent for some less-than-omnipotent being to create a stone too heavy for it to lift. So, this restricted version of omnipotence apparently does not solve the problem.

But certainly, one must admit that there is something inconsistent about an omnipotent being creating such a stone. So, one might try to restrict the domain of quantification so that omnipotence requires the ability to do only those actions appropriate for whatever kind of being it is.

$$
x \text { is omnipotent } \leftrightarrow \forall y \forall z((\varphi(z) \rightarrow \diamond B(z, y)) \rightarrow(\varphi(x) \rightarrow \diamond B(x, y)))
$$

The contention here is that an omnipotent being must be able to bring about all events possible for anything of kind $\varphi$.

Many have pointed out, however, that this response makes the property of 'being omnipotent' all too easily gained. Consider the omnipotence of McEar, who only has the capability of scratching his ear. ${ }^{12}$ This notion of omnipotence seems to radically diverge from the conception of omnipotence as absolutely unrestricted.

\subsection{Inconsistent Responses}

Some theists have denied premise (ii). ${ }^{13}$ From the possibility of God making an unliftable rock, it does not follow that God actually fails to be omnipotent unless God actually does create such a rock. Hence, God's actual capacity to do so is compatible with his omnipotence so long as he does not act on it. Of course, in any possible world where God makes an unliftable rock it follows that he is not omnipotent in that possible world. Given that God is necessarily omnipotent, this view commits one to the possibility of God's being both omnipotent and not. This view, then, is

\footnotetext{
${ }^{11}$ Mavrodes [20].

${ }^{12}$ See Plantinga [24, p. 70] and LaCroix [I I, p. I 87]. The main point behind these examples dates back to Ockham.

${ }^{13}$ Notably, Swinburne [36] has argued for this view, while rejecting that God is essentially or necessarily omnipotent.
} 
a form of light dialetheism.

But light dialetheism is a slippery slope that can lead to full-strength dialetheism. In this case one might grant the rejection of (ii) but replace it with (ii*): necessarily, if God makes a stone he cannot lift, then it is not the case that he can bring about every event. But (ii*) leads to problems, as the following argument shows. Let $g$ be 'God', and $s$ be the relevant unliftable-stone-making event.

i. $\square \forall y \diamond B(g, y)$

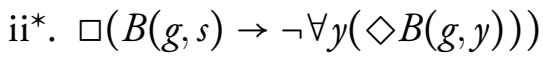

iii. $\diamond B(g, s)$

iv. $\diamond \neg \forall y(\diamond B(g, y))$

v. $\neg \diamond \neg \forall y(\diamond B(g, y))$

vi. $\diamond \neg \forall y(\diamond B(g, y)) \wedge \neg \diamond \neg \forall y(\diamond B(g, y))$
[Omnipotence of $g$ ]

[Premise]

[Premise]

[MP (ii*), (iii)]

[equivalent to (i)]

[Conjunction of (iv), (v)]

Notice that (vi) is a sentence of the form $A \wedge \neg A-$ an actual contradiction. And so even using rules acceptable in a paraconsistent setting, allowing for the possibility of God bringing about a state-of-affairs contradictory to his omnipotence entails full-strength dialetheism.

It may be argued that $\left(\mathrm{ii}^{*}\right)$ is intuitively too strong. Frankfurt [13] has pointed out that if we are allowing God to perform a contradictory action - that of creating the unliftable stone why should he not be able to perform an additional contradictory action - that of lifting the unliftable stone? If this is allowed, then God can lift the unliftable stone. If it is possible for God to lift the unliftable stone even in a possible situation where he cannot, then in that situation there is nothing he cannot do. Hence, (ii*) as it stands appears false. This line of argument would appear to avoid the conclusion that if it is possible for God to make an unliftable rock then it is impossible. 
Or so it would seem. Given standard paraconsistent tools, the conclusion is not avoided. If a stone is to be truly unliftable, it must be false in every world that God brings about the lifting of it $(l): \nu_{w}(\neg B(g, l))$ is designated for all worlds $w$. And if God truly lifts the unliftable stone, then it must be true in some world that God brings about the lifting of it: $\nu_{w^{\prime}}(B(g, l))$ is designated for some world $w^{\prime}$. So, $\nu_{w}(\diamond(\neg B(g, l) \wedge B(g, l)))$ is also designated - a possibly true contradiction. But in modal paraconsistent logics like $L P$, the truth of possible contradictions implies the truth of actual ones. ${ }^{14}$ In general:

$$
\diamond(A \wedge \neg A) \vDash_{L P} \diamond(A \wedge \neg A) \wedge \neg \diamond(A \wedge \neg A)
$$

Applied above, the result shows that the dialetheic theist is committed to it being possible and impossible that God lift the unliftable stone. The contradiction 'spreads' from a merely possible world to a contradiction in the actual world. It looks as though light dialetheists are committed to full-blown dialetheism.

But full-strength dialetheism has its upside. After all, in our paraconsistent setting $\diamond(\neg B(g, l)$ does not rule out $\forall y \diamond B(g, y)$, even when the universal quantifier ranges over events like the lifting of and unliftable rock. It still has a designated value, which means we can accept that for all $y$ it is possible for God to bring about $y$; we can endorse the omnipotence of God.

But this upside has a downside: God's omnipotence requires omnipotence to be an inconsistent property. In other words, given the actual contradiction, we have $\nu_{w}(\neg \diamond B(g, l))=\frac{1}{2}$. But then we have $\nu_{w}(\exists y \neg \diamond B(g, y))=\frac{1}{2}$. (This last step relies relies on our treatment of quantifiers ranging over a constant domain at all possible worlds. On a variable domain treatment, we would still be stuck with the fact that it is possible that there is an event that is impossible for

\footnotetext{
${ }^{14}$ This point is due to Restall [33].

${ }^{15}$ Assume $\nu_{w}(\diamond(A \wedge \neg A))$ is designated; so $\max \left\{\nu_{w^{\prime}}(A \wedge \neg A)\right\} \in\left\{1, \frac{1}{2}\right\}$ which can only happen if $\max \left\{\nu_{w^{\prime}}(A \wedge\right.$ $\neg A)\}=\frac{1}{2}$. So $\nu_{w}(\diamond(A \wedge \neg A))=\frac{1}{2}$. But then $\nu_{w}(\neg \diamond(A \wedge \neg A))=\frac{1}{2}$. Hence, $\nu_{w}(\diamond(A \wedge \neg A) \wedge \neg \diamond(A \wedge \neg A))=\frac{1}{2}$, which is designated.
} 
God, together the actual impossibility that God both lift and not lift the stone.) So the dialetheic theist must endorse the claim that there is some event that God cannot actually bring about, or equivalently $\neg \forall y \diamond B(g, y)$ the claim that it's not the case that God can bring about everything. And this by definition would mean that God both is and also is not omnipotent. That is, God's omnipotence is had inconsistently; his character is self-contradictory.

\section{Milnés Paradox}

Dialetheic theism can also handle some more recent paradoxes of omniscience. One such paradox advanced by Peter Milne [22] concerns the sentence $S$ below.

(S) No omniscient being knows that which the sentence $S$ expresses.

Let $O$ be an omniscience predicate and $K$ a binary predicate where $K(x, y)$ means $x$ knows $y$. We use ${ }^{\ulcorner} S^{\urcorner}$as a name for the sentence $S$. Then (S) is equivalent to $\neg \exists x\left(O x \wedge K\left(x,{ }^{\ulcorner} S^{\urcorner}\right)\right)$.

Milne argues that $S$ is a paradox for omniscience. His argument is that if we assume that there is some omniscient being $g$ who knows that $S$, we get a contradiction.
i. $O g \wedge K\left(g,{ }^{\ulcorner} S^{\urcorner}\right)$
[Assumption]
ii. $K\left(g,{ }^{\ulcorner} S^{\urcorner}\right)$
[(i), Simplification]
iii. $S$
[(ii), Factivity of Knowledge]
iv. $\neg \exists x\left(O x \wedge K\left(x,{ }^{\ulcorner} S^{\urcorner}\right)\right)$
[(iii), Substitution]
v. $\neg\left(O g \wedge K\left(g,{ }^{\ulcorner} S^{\urcorner}\right)\right)$
[(iv), Instantiation]

The supposition that there is an omniscient being implies its negation.

Given the similarities between $S$ and Liar-like paradoxes (especially the Knower paradox), one might attempt a consistent response by requiring only that God know consistent propositions. But unlike Liar sentences, $S$ does have a consistent interpretation. If there are no omniscient 
beings, $S$ is straightforwardly true. So, even though it is self-referential, there is nothing selfundermining about $S$. Milne concludes then that either omniscient beings do not exist, or if they do we must be dialetheists. ${ }^{16}$

One might object that the dialetheic perspective should be rejected since it appears to require failures of the factivity of knowledge. If one allows that God can know contradictions, we allow that God can know some false propositions. This is correct so far as it goes; but for the dialetheist, contradictions while being false may also be true. Only contradictions which are true (and false) can be known. Hence, the factivity of knowledge is preserved. ${ }^{17}$

We saw that a dialetheic approach to the paradox of the stone led to the conclusion that God's omnipotence was an inconsistent attribute. Does the same hold true for omniscience? Here is a reason to think that it does.

Given a truth predicate $T$ that holds only for true (and inconsistently true) sentences, here is a definition of omniscience.

$$
x \text { is omniscient } \leftrightarrow \forall y(T(y) \leftrightarrow K(x, y))
$$

Given that ${ }^{\ulcorner} S^{\urcorner}$can be plugged in for $y, \nu_{w}\left(T\left({ }^{\ulcorner} S^{\urcorner}\right)\right)=\frac{1}{2}$ and $\nu_{w}\left(K\left(g,{ }^{\ulcorner} S^{\urcorner}\right)\right)=\frac{1}{2}$, then $\nu_{w}\left(T\left({ }^{\ulcorner} S^{\urcorner}\right) \leftrightarrow\right.$ $\left.K\left(x,{ }^{\ulcorner} S^{\urcorner}\right)\right)$will be both true and false. ${ }^{18}$ Supposing God knows every other truth, we will have it that the minimum value of $\left\{\nu_{w}(T(c) \rightarrow K(x, c)\right.$ : for all names $c\}$ can never be higher than $\frac{1}{2}$, and hence that God is both omniscient and not.

What this shows is that God, by virtue of knowing a contradiction, has his omniscience is inconsistently. Omniscience, like omnipotence, is inconsistently attributed to God. There are two lines of reply: one might bite the bullet and accept this as another aspect of dialetheic theism, or one might employ other formal tools to avoid the consequence (options are explored in $\$ 4$ ).

\footnotetext{
${ }^{16}$ In fact, Milne's stated conclusion is not merely that any theist must be a dialetheist, but also that God himself must be a dialetheist. After all, any omniscient being, therefore, must know that $S$ is contradictory, and know that he knows it.

${ }^{17}$ See Priest [30, \$16.7].

${ }^{18}$ This holds in $D K Q$, by axioms I and VI (see Appendix).
} 


\section{Grim's Paradox}

Grim $\left[\mathrm{I}_{4}, \mathrm{I}_{5}\right]$ has leveled an objection to the existence of omniscient beings by arguing that there is no set of all truths. The objection has parallels to the set-theoretic paradoxes (e.g. Russell's paradox $\left.{ }^{19}\right)$, which are among the main motivations for dialetheism. ${ }^{20}$

Suppose for reductio there is a set $A$ of all truths. For every subset $s_{i}$ of $A$ and $a \in A$, there exists a truth expressed by one of the following two sentences: $a \in s_{i}$ or $a \notin s_{i}$. So, one of these two sentences will be in $A$, for every $s_{i}$. Thus, there are at least as many members of $A$ as there are members of the powerset of $A$. But this contradicts Cantor's Theorem, which states that for any set $X$, the cardinality of $X$ is strictly less than the cardinality of its powerset. Therefore, there is no set of all truths.

Grim thinks this argument has application to omniscience.

Were there an omniscient being, what that being would know would constitute a set of all truths. But there can be no set of all truths, and so can be no omniscient being. $([$ I 5 , p. 356])

The argument goes something like this:

$$
\begin{array}{lr}
\text { i. } \exists x \forall y(T(y) \leftrightarrow K(x, y)) \rightarrow \exists z\left(z=\left\{S: T\left({ }^{\ulcorner} S^{\urcorner}\right)\right\}\right) & \text {[Premise] } \\
\text { ii. } \neg \exists z\left(z=\left\{S: T\left({ }^{\ulcorner} S^{\urcorner}\right)\right\}\right) & \text {[Grim's proof] }
\end{array}
$$

And given our above definition of omniscience, this just is the claim that there are no omniscient beings.

\footnotetext{
${ }^{19}$ More precisely, it is directly analogous to Russell's paradox of propositions

${ }^{20}$ See Priest [27, chs. 2, Io].
} 


\section{I Consistent Responses}

One line of response to this argument is to reject premise (i). ${ }^{21}$ As Plantinga [I7] has rightly noted, the first premise relies on the assumption that quantification essentially involves sets (or set-like entities). Even if we grant that there is no set of all truths, why should it follow that there is no being that knows all truths?

Bringsjord [9] offers two lines of response to Grim's paradox of omniscience. The first consciously parallels the more restrictive consistent responses to omnipotence. He rejects the unrestricted definition

$$
x \text { is omniscient } \leftrightarrow \forall y(T(y) \leftrightarrow K(x, y))
$$

and proposes a restricted definition of omniscience: ${ }^{22}$

$$
x \text { is omniscient } \leftrightarrow \forall y((T(y) \wedge \diamond K(x, y)) \leftrightarrow K(x, y))
$$

Here $x$ is omniscient just when $x$ knows every truth $x$ can know. Now there are problems with this revised definition. As Grim [I6] notes, the counterexamples to restricted versions of omnipotence can be adapted to counterexamples here (consider McIg, who is necessarily such that he can only ever know that he is conscious). Moreover, given the admission that there are truths God cannot know, we would need independent motivation for the claim that set-theoretic truths featured in Cantorian arguments are the kind of truths God cannot know - especially since we can.

Bringsjord's second line of response will be more useful for our purposes, as it is a precursor

\footnotetext{
${ }^{21}$ Others e.g. Beall [I] reject premise (ii).
}

${ }^{22}$ Bringsjord's actual definition is

$$
x \text { is omniscient } \leftrightarrow \forall y(\diamond K(x, y) \leftrightarrow K(x, y))
$$

But this clearly cannot be right, since it would bring about failures of the factivity of knowledge: let $S$ be some contingent but actually false proposition. It's possible that God knows $S$; in fact, at any world in which ' $S$ ' is true, God knows it. But that cannot entail that God actually knows $S$, since $S$ is actually false by supposition. The definition below solves this problem. 
to the dialetheic solution. He suggests that the paradox can be avoided by rejecting (ii) and doing without the Power Set axiom of Zermelo-Frankl set theory $(Z F)$ :

$$
\forall z \exists y \forall x(x \in y \leftrightarrow \forall w(w \in x \rightarrow w \in z))
$$

By denying the above axiom, and hence countenancing an alternative set-theory, Bringsjord thinks the theist can avoid Cantor's Theorem and resolve the trouble. In response, Grim [I6] argues that a similar argument can be given via other axioms of $Z F$ (i.e. Separation), and so any such approach would require even more drastic revisions to set theory. But it may be that some alternative set theory can do the job without having to reject too much of $Z F$. This, I think, is the most plausible dialetheic line of response.

\subsection{Inconsistent Set Theory and the Universal Set}

Whether all quantification is quantification over set-like totalities is deeply controversial and itself tied up with Russell's paradox. ${ }^{23}$ Dialetheists (Priest [26, ch. I7]) have defended the principle that quantification presupposes a corresponding set-like domain. For decades, dialetheic logicians have been after an alternative set theory that vindicates the naïve conception of a set, given by the Naïve Comprehension Schema and the Axiom of Extensionality.

Naïve Comprenhension is as follows:

$$
\exists y \forall x(x \in y \equiv \varphi(x))
$$

Here $\varphi(x)$ is any predicate with just $x$ free. The axiom of Extensionality is: ${ }^{24}$

$$
\forall z \forall y \forall x(x \in y \equiv x \in z) \supset y=z
$$

\footnotetext{
${ }^{23}$ See e.g [3 I]. Simmons [35] argues that if we accept that the concepts of 'set' or 'truth' are indefinitely extensible, then we can save a version of omniscience.

${ }^{24}$ We have not given semantic clauses for 's'. So, ' $y=z$ ' is treated as an abbreviation for $\forall w(y \in w \equiv z \in w)$.
} 
Call the instances of Naïve Comprehension and Extensionality ' $N$, for naïve set theory. Naïve set theory is typically rejected because it generates inconsistency via the Russell set: just let $\varphi(x)$ be $\{x: x \notin x\}$ in the Comprehension Schema. But if our background logic is paraconsistent this can be tolerated. In order to examine one such naïve set theory, we simply add a primitive membership predicate $(\epsilon)$ to $L P$ and look at the consequences of $N$ within $L P$. (We stick with $L P$ here primarily because the arguments are more tractable. Set theory has been developed in our official logic $D K Q([27$, p.25I $])$ and is also non-trivial [8]. $)^{25}$

It can be shown that nearly all of the axioms of $Z F$ are consequences of $N$. I say 'nearly' because the only axiom not included in the consequences of $N$ is the axiom of Foundation or Regularity: ${ }^{26}$

$$
N \sharp_{L P} \forall z(\exists y(y \in z) \supset \exists y(y \in z \wedge \neg \exists x(x \in y \wedge x \in z)))
$$

We even have Power Set

$$
N \vDash_{L P} \forall z \exists y \forall x(x \in y \equiv \forall w(w \in x \supset w \in z))
$$

which is an instance of Naïve Comprehension with $\varphi(x)$ defined as $(w \in x \supset w \in z)$.

Grim argued contra Bringsjord that denying Power Set was not sufficient to get around the paradox. What is interesting about the current approach is that it is not even necessary. This is due to the fact that we have the existence of the universal set in the current framework:

$$
N \vDash_{L P} \exists x \forall y(y \in x)
$$

(To prove this, assume for reductio that there is no universal set; one can show that the set of all non-universal sets must be a universal set. ${ }^{27}$ )

\footnotetext{
${ }^{25}$ See also $[38,39]$ for recent developments.

${ }^{26}$ For a proof, see Restall [32, p. 426].

${ }^{27}$ See Restall [32, p. 426].
} 
Given we have a universal set, $U$, the power set of $U$ clearly cannot include anything more than the original set. This does not run afoul of the Power Set axiom since $\forall z(z \subseteq U \supset z \in U)$; that is, $U$ contains all of its own subsets. $U$ is a counterexample to Cantor's Theorem which fails in $N$. So Grim's paradox doesn't get off the ground unless we have independent reason for thinking that the set of truths cannot be mapped one-to-one with its power set.

More to the point: Naïve Comprehension gives a set of all truths:

$$
N \vDash_{L P} \exists y \forall x(x \in y \equiv T(x))
$$

Call this set $T$. So premise (ii) of Grim's argument is (at least) false. Is it also true? It will be if $T$ is an inconsistent; that is, if there are some members that are also non-members, or if some truths are also false. In $N$, there are clearly inconsistent sets: the Russell set (which exists by plugging $x \notin x$ into Naïve Comprehension) is an example:

$$
N \vDash_{L P} \exists y \forall x(x \in y \equiv x \notin x)
$$

So according to $N$, there both is and is not a set of all the propositions that God knows. Premise (ii) of Grim's argument is both true and false, and so is the consequent of premise (i). If premise (i) is to receive a designated value, then it's antecedent must also be true and false. ${ }^{28}$ As a result, the conclusion (iii) is also both true and false. We are in a position which by now will seem quite familiar: it turns out that God is both omniscient and not omniscient. Again, dialetheism about the set of all truths 'spreads' into God's nature being inconsistent.

\section{Limiting the Spread of Inconsistency}

We have seen a general pattern emerge from these discussions. The dialetheic solution to the various paradoxes of the divine attributes entail, by virtue of paraconsistent logic, that the attributes

\footnotetext{
${ }^{28}$ This follows in $D K Q$ from contraposition.
} 
themselves are inconsistently had by God. We can turn the screws even tighter: if omniscience and omnipotence are both true of and false of God, then paraconsistent logic gives us the claim $\exists x(x$ is omniscient $\wedge x$ is omnipotent $)$ is both true and false as well. In other words, the very claim that an omni-being exists is inconsistent.

I have argued that these are logical consequences of dialetheic theism. But it is worth pausing to notice that these consequences rest on two important assumptions: firstly, they rest on the logical principle of contraposition; secondly, they rest on treating 'omniscience' and 'omnipotence' as defined predicates.

\section{S.I Rejecting Contraposition}

Both the material conditional in $L P$ and the primitive conditional in $D K Q$ contrapose.

$$
\begin{gathered}
A \supset B \vDash_{L P} \neg B \supset \neg A \\
A \rightarrow B \vdash_{D K Q} \neg B \rightarrow \neg A
\end{gathered}
$$

Recall that in $L P, A \supset B$ is an abbreviation for $\neg A \vee B$; so $\neg B \supset \neg A$ is an abbreviation for $\neg \neg B \vee \neg A$, which by double negation is $B \vee \neg A$. The validity of contraposition in $D K Q$ can be seen in axiom VI and the rule form derived via RII (see Appendix).

This assumption was crucial throughout our discussion. Consider again our working definition of 'omnipotence'.

$$
x \text { is omnipotent } \leftrightarrow \forall y(\diamond B(x, y))
$$

This definition is a biconditional, and hence has two directions. Of particular relevance is the leftto-right direction; which when contraposed is $\neg \forall y(\diamond B(x, y)) \rightarrow \neg(x$ is omnipotent $)$. I argued in $\$ 2.2$ that the dialetheic theist must accept that $\neg \forall y(\diamond B(g, y))$ and concluded that God is not omnipotent. Contraposition played the same role in $\S_{3}$ regarding the definition of omniscience.

In $\$ 4$, we can see the use of contraposition indirectly in Grim’s paradox. The final step in the 
argument is a direct application of modus tollens on premise (i), which is closely related to the contraposability of the conditional.

But not all paraconsistent logics permit contraposition and modus tollens, however. Many paraconsistent logics fail to validate either inference. The weak relevant systems $K_{4}$ and $N_{4}$ are good examples (Priest $[28, \mathrm{ch} .9])$. In $D K Q$, it is very natural to define a non-contraposable conditional in the logic. To do so we add a logical constant $t$ that obeys the two-way rule:

$$
A \dashv \vdash_{D K Q} t \rightarrow A
$$

The $t$-constant may be thought of as the conjunction of all (actual) truths. We can then define a conditional connective in terms of it thus:

$$
A \mapsto B:=(A \wedge t) \rightarrow B
$$

This defined conditional does not contrapose:

$$
A \mapsto B \nvdash_{D K Q} \neg B \mapsto \neg A
$$

We can think of $t$ as taking the value $\frac{1}{2}$, since the conjunction of all truths will contain at least some dialetheia. But then $\nu(A)=1$ and $\nu(B)=\frac{1}{2}$ gives a countermodel.

The upshot is that, if a dialetheic theist can make the case that omnipotence and omniscience should be defined using $\mapsto$ rather than $\rightarrow$, they can avoid inconsistent omni-attributes. The reply is not $a d$ hoc if the failure of contraposition can be motivated independently by dialetheists. Consider the purported entailment from 'All $A$ s are $B s$ ' to 'All non- $B$ s are non- $A s$ '. Suppose further that $B$ is an inconsistent property. Should something's being a non- $B$ entail it's being a non- $A$ ? As is an example, imagine there were a swan that was both black and not black; would it follow that it wasn't a swan? Why? (Answering that everything follows from a black and non-black swan 
would be to beg the question against paraconsistency.)

A more pressing reason for rejecting contraposition is that the following three principles are mutually problematic.

$$
\begin{gathered}
A \rightarrow B, A \vDash B \\
A \rightarrow B \vDash \neg B \rightarrow \neg A \\
A \vDash B \rightarrow A
\end{gathered}
$$

As Beall et. al. [5] have noted, they jointly force the validity of ECQ, and hence cannot all be included in any paraconsistent logic.

$$
\frac{\neg B \quad \frac{B}{\neg B \rightarrow \neg}}{\neg A}
$$

So any paraconsistent dialetheist must reject one of these three principles on pain of triviality. The $L P$ material conditional $\supset$ fails the first (modus ponens); the primitive $D K Q$ conditional $\rightarrow$ fails the last (weakening); and the defined $D K Q$ conditional fails contraposition. There is strong reason to think that contraposition is least motivated from a dialetheic perspective. Rejecting contraposition, then, is an avenue for the dialetheic theist to limit the spread of contradictions and maintain that God's nature and existence remains consistent even if his actions and knowledge are not.

\subsection{Primitive Attributes}

I want to briefly explore a second avenue for limiting the spread of contradictions. We have been treating omnipotence and omniscience as defined predicates, but we might wish to reject that treatment. On the proposed view, the divine attributes cannot be analyzed by necessary and sufficient conditions; they are primitive attributes. We could for instance accept that there 
are sufficient conditions for omnipotence, i.e. the right-to-left direction of our biconditional definitions, without requiring omnipotence to be logically defined by that condition. Similarly for omniscience.

On this proposal, there is no need for inconsistency in divine actions or inconsistency in the set of known truths to bleed back into inconsistencies in the divine nature. In fact, there is a way to formally ensure that the divine attributes remain consistent in paraconsistent logics like $L P$ and $D K Q$ due to Priest $[27, \$ 8.5]$ and developed by Beall [3]. Where $\perp$ is a propositional constant such that $\nu_{w}(\perp)=0$ for all worlds $w$, we can make any sentence $A$ consistent by adding the following principle as a primitive rule of our theory.

$$
A \wedge \neg A \vDash \perp
$$

More generally, we can make any $n$-ary predicate $P$ consistent by adding the following:

$$
\exists x_{1} \ldots \exists x_{n}\left(P\left(x_{1}, \ldots x_{n}\right) \wedge \neg P\left(x_{1}, \ldots x_{n}\right)\right) \vDash \perp
$$

So if we added the corresponding axioms for our two primitive unary predicates expressing omniscience and omnipotence, we would guarantee that the divine attributes were consistent and preserve the simple truth of God's existence.

\section{Semantic versus Metaphysical Dialetheism}

To some, these logical maneuvers may not inspire confidence: dialetheic theists will need to offer additional philosophical motivation (perhaps they can borrow from the literature on dialetheism) for whatever routes they choose. Alternatively, I would suggest that dialetheic theists simply accept the logical consequences of the view, and temper the philosophical significance of inconsistencies in God's attributes by appealing to another well-known distinction in the literature: Mares' [I9] distinction between semantic and metaphysical dialetheism. Metaphysical dialetheism is the view 
that "there are things in the world that are actually inconsistent" while semantic dialetheism is the view that "there are no inconsistencies in things but $[\ldots]$ inconsistencies arise because of the relationship between language and the world" $(256){ }^{29}$

Consistency, it is sometimes thought, is a property of representations of the world and not of the world itself. Compare Swinburne:

...[L] ogical necessity is at root a feature of actual human sentences and how they are used. It governs language, and not the world. ([36, p. 96])

On this view, to think that God himself is metaphysically inconsistent would be project a feature of human representations on to God. Theologians often regard projections of our forms of thought onto the being of God as a particularly pernicious kind of error.

Semantic dialetheic theists will maintain that our best descriptions of God in language requires inconsistency, but we need not think these inconsistencies are univocal and literally accurate descriptions of the metaphysical characteristics of God. Descartes seems to hold precisely this view:

[Divine power] involves a contradictory conception; that is, is inconceivable by us. But I do not think we should ever say of anything that it cannot be brought about by God. I would dare not even say that God cannot make a mountain without a valley, or bring it about that $\mathrm{I}$ and 2 are not 3 . I merely say that he has given me such a mind that I cannot conceive a mountain without a valley or a sum of I and 2 which is not 3; such things involve a contradiction in my conception. ('To Arnauld', [I 2, p. 359])

The idea sits well within certain Christian traditions of theology (e.g. the apophatic and voluntarist traditions) that emphasize God's transcendence beyond the created order, and God's aseity or absolute independence from anything outside himself. So, there are theological motivations

\footnotetext{
${ }^{29}$ Beall [2], Bobenreith [7], Kroon [18], and Mares [19] are self-avowed semantic dialetheists. For Priest's discussion on whether he is a metaphysical dialetheist, see Priest [27, pp. 299-302].
} 
for semantic dialetheic theism, according to which it is merely our representations of God that are inconsistent, perhaps due to underlying intellectual or linguistic limitations. ${ }^{30}$

I have not attempted to answer every possible objection to dialetheic theism. ${ }^{31}$ My aim has been primarily exploratory — to see what insights might be gained from contemporary developments in paraconsistent logic.

Dialetheic theism is a logically coherent (even if inconsistent!) view, with well-studied and comprehensive formal underpinnings. It solves a range of paradoxes regarding the divine attributes, and that is something to be said in its favor. The view has some untoward consequences, but I've suggested avenues toward mitigating them. I do not expect the view to be popular; I am not recommending it be believed. But if we have learned anything from the literature on the semantic and set-theoretic paradoxes, it is that dialetheism - when supplemented with rigorously developed paraconsistent logics — has proven to be a serious contender. Is dialetheic theism is a serious contender? I don't know, but developing the view paying careful attention to the resources of paraconsistent logic is the first step toward finding out. ${ }^{32}$

\footnotetext{
${ }^{30}$ For further motivations from Christian theology, see Beall [4].

${ }^{31}$ For a good selection of objections to a related view called universal possibilism see Plantinga [23]; see McCann [2 I] for discussion. Some have suggested dialetheism will make the Problem of Evil more difficult for the theist. See Conee $[\mathrm{Io}, \mathbb{\S V I}]$.

${ }^{32}$ Thanks to David Aiken, Don Baxter, Tim Baylor, Colin Caret, Filippo Casati, Mark Gedney, Alexus McLeod, Hitoshi Omori, Andrew Parisi, Greg Restall, Dave Ripley, Kevin Scharp, Patrick Todd, and Alan Torrance (among others who I am surely forgetting) for discussion of these and related ideas. Special thanks go to Jc Beall for discussions on these topics spanning a decade. Thanks to three anonymous referees for this journal for detailed comments on earlier versions of this paper.
} 
References

[I] Beall, J. A neglected response to the grim result. Analysis 60.I (2000), 38-4I.

[2] Beall, J. True and false - as if. In The Law of Non-Contradiction: New Philosophical Essays, G. Priest, J. Beall, and B. Armour-Garb, Eds. Oxford University Press, Oxford, 2004, ch. I 2.

[3] BeALL, J. A simple approach towards recapturing consistent theories in paraconsistent settings. The Review of Symbolic Logic 6, 4 (2013), 755-764.

[4] Beall, J. Christ: a contradiction. Journal of Analytic Theology (forthcoming).

[5] Beall, J., Brady, R. T., Hazen, A. P., Priest, G., and Restall, G. Relevant restricted quantification. Journal of Philosophical Logic 35, 6 (2006), 587-598.

[6] Beall, J., And Cotnoir, A. J. God of the gaps. Analysis (forthcoming).

[7] Bobenreith, A. Paraconsistency and the consistency or inconsistency of the world. In Proceedings of the Third World Congress on Paraconsistency (2006), J.-Y. Béziau and W. A. Carnelli, Eds., vol. 4, Studies in Logic and Practical Reasoning, Elsevier Science.

[8] Brady, R. Universal logic. CSLI Publications Stanford, 2006.

[9] Bringsjord, S. Grim on logic and omniscience. Analysis 49 (I987), I 86-I89.

[ı] Conee, E. The possibility of power beyond possibility. Philosophical Perspectives 5 (I99I), 447-473.

[i I] Croix, R. L. The impossibility of defining omnipotence. Philosophical Studies 32 (I977), I 8 I-I 90.

[i 2] Descartes, R. The Philosophical Writings of Descartes, vol. 3. Cambridge University Press, Cambridge, I984-I991. 
[13] Frankfurt, H. The logic of omnipotence. Philosophical Review 73, 2 (April I 964), 262-263.

[14] Grim, P. Some neglected problems of omniscience. American Philosophical Quarterly 20 (1983), $265-276$.

[i 5] Grim, P. Logic and the limits of truth. Nô̂s 22 (I988), 34I-367.

[i6] Grim, P. On omniscience and a 'set of all truths': a reply to bringsjord. Analysis 50, 4 (October 1990), 27I-276.

[i 7] Grim, P., and Plantinga, A. Truth, omnipotence, and cantorian arguments: An exchange. Philosophical Studies 7I (1993), 267-306.

[i 8] Kroon, F. Realism and dialetheism. In The Law of Non-Contradiction: New Philosophical Essays, G. Priest, J. Beall, and B. Armour-Garb, Eds. Oxford University Press, Oxford, 2004, ch. I 5 .

[19] Mares, E. Semantic dialetheism. In The Law of Non-Contradiction: New Philosophical Essays, G. Priest, J. Beall, and B. Armour-Garb, Eds. Oxford University Press, Oxford, 2004, ch. I6.

[20] Mavrodes, G. Some puzzles concerning omnipotence. Philosophical Review 72 ((1963)), $22 I-223$.

[2 I] McCann, H. Creation and the Sovereignty of God. Indiana University Press, 20 I 2.

[22] Milne, P. Omniscient beings are dialetheists. Analysis 76, 3 (July 2007), 250-25 I.

[23] Plantinga, A. Does God Have A Nature? Marquette University Press, i 980.

[24] Plantinga, A. God and Other Minds. Cornell University Press, I 990.

[25] Priest, G. The logic of paradox. Journal of Philosophical Logic 8, 4 (I979), 2 I 9-24I.

[26] Priest, G. Beyond the Limits of Thought, 2nd ed. Oxford University Press, Oxford, 2002. 
[27] Priest, G. In Contradiction, 2nd ed. Oxford University Press., 2006.

[28] Priest, G. An Introduction to Non-Classical Logic, 2nd ed. Cambridge University Press, Cambridge, 2008.

[29] Priest, G. Many-valued modal logics: a simple approach. The Review of Symbolic Logic I, 2 (2008), 190-203. Special Issue.

[30] Priest, G. Towards Non-Being, 2nd ed. Oxford University Press, 20 i 6.

[3 I] Rayo, A., and Uzquiano, G., Eds. Absolute Generality. Oxford University Press, 2006.

[32] Restall, G. A note on naive set theory in LP. Notre Dame Journal of Formal Logic 30 (I992), $422-432$.

[33] Restall, G. Paraconsistent logics! Bulletin of the Section of Logic of the Polish Academy of Sciences 26 (1997), I 56-163.

[34] Rudavsky, T., Ed. Divine Omniscience and Omnipotence in Medieval Philosophy: Islamic, Jewish, and Christian Perspectives. No. 25 in Synthese Historical Library. Springer, I984.

[35] Simmons, K. On an argument against omniscience. Nô̂s 27 (I993), 22-33.

[36] Swinburne, R. The Christian God. Oxford University Press, I 994.

[37] Vitti, J. Weekend at burnsie’s. FOX, o7 April 2002. The Simpsons: Season I 3 Episode i6.

[38] Weber, Z. Transfinite numbers in paraconsistent set theory. Review of Symbolic Logic 3, I (2010), 7I-92.

[39] Weber, Z. Transfinite cardinals in paraconsistent set theory. Review of Symbolic Logic 5, 2 (20I2), 269-293.

[40] Weber, Z., and Cotnoir, A. J. Inconsistent boundaries. Synthese I92, 5 (20 I 5), I 267-I 294. 


\section{Appendix}

Below is a presentation of the relevant logic $D K Q .{ }^{33}$ The language is that of first-order logic.

All instances of the following axiom schemata are theorems:

I. $A \rightarrow A$

IIa. $(A \wedge B) \rightarrow A$

IIb. $(A \wedge B) \rightarrow B$

III. $A \wedge(B \vee C) \rightarrow((A \wedge B) \vee(A \wedge C))$

Distribution

IV. $((A \rightarrow B) \wedge(B \rightarrow C)) \rightarrow(A \rightarrow C)$

Conjunctive Syllogism

V. $((A \rightarrow B) \wedge(A \rightarrow C)) \rightarrow(A \rightarrow B \wedge C)$

VI. $(A \rightarrow B) \leftrightarrow(\neg B \rightarrow \neg A)$

Contraposition

VII. $A \leftrightarrow \neg \neg A$

Double Negation Elimination

VIII. $A \vee \neg A$

Excluded Middle

IX. $\forall x A \rightarrow A(a / x)$

X. $\forall x(A \rightarrow B) \rightarrow(A \rightarrow \forall x B)$

(with $x$ not free in $A$ )

XI. $\forall x(A \vee B) \rightarrow(A \vee \forall x B)$

(with $x$ not free in $A$ )

The following rules are valid:

RI. $A, B \vdash A \wedge B$

Adjunction

RII. $A, A \rightarrow B \vdash B$

Modus Ponens

RIII. $A \vdash \forall x A$

Universal Generalization

RIV. $A \rightarrow B, C \rightarrow D \vdash(B \rightarrow C) \rightarrow(A \rightarrow D)$

Hypothetical Syllogism

The following meta-rules preserve validity:

$$
\frac{A \vdash B}{A \vee C \vdash B \vee C} \quad \frac{A \vdash B}{\exists x A \vdash \exists x B}
$$

${ }^{33}$ This presentation follows closely that of [40]. 